PONTIFÍCIA UNIVERSIDADE CATÓLICA DO RIO DE JANEIRO

\title{
Aversão ao Risco por Gênero em Loterias Escalonadas
}

Beatriz Nogueira Margulies

Trabalho de Conclusão de Curso

Centro de Ciências socials - CCS

DEPARTAMENTO de ADMINISTRAÇÃo

Graduação em Administração de Empresas 
Beatriz Nogueira Margulies

\section{Aversão ao Risco por Gênero em Loterias Escalonadas}

Trabalho de Conclusão de Curso

Trabalho de Conclusão de Curso, apresentado ao programa de graduação em Administração da PUC-Rio como requisito parcial para a obtenção do titulo de graduação em Administração.

Orientador : Marcelo Cabús Klotzle

Rio de Janeiro

Novembro de 2015. 
"Great love and great achievements involve great risk"

Dalai Lama

"In many cases, what looks like risk-taking doesn't take courage at all; it's just unrealistic optimism. Courage is a willingness to take the risk once you know the odds; optimistic overconfidence means you are taking the risk because you don't know the odds. There's a big difference."

Daniel Kahneman 


\section{Agradecimentos}

Agradeço ao meu orientador Dr. Marcelo Klotzle pelo apoio, orientação e confiança na elaboração deste trabalho e a todos os meus professores da PUCRio em especial Roberto Uchoa e Veranise Dubeux, pela dedicação e empenho acima do comum por educar. Bons professores e orientadores conseguem estimular a propagação de seus ensinamentos para além de seus alunos, contribuindo verdadeiramente para um mundo melhor.

Agradeço aos meus pais, minha irmã e meus avós que sempre me mostraram a importância da educação. Serei eternamente grata pelo seu apoio incondicional que foi fundamental para que eu conquistasse meus objetivos.

Agradeço em especial aos meus amigos que dividiram comigo momentos de nervosismo e de alegria, e muitos questionamentos nem sempre acadêmicos. Estar cercada por pessoas interessantes e positivas certamente é um fator que me estimulou a sempre buscar por mais.

Finalmente, agradeço à PUC-Rio. O que vivi em sala de aula e nas longas horas de pilotis será sempre lembrado com muito carinho e saudade. 


\section{Resumo}

Nogueira Margulies, Beatriz. Aversão ao risco por gênero em loterias escalonadas. Rio de Janeiro, 2015. 32 p. Trabalho de Conclusão de Curso - Departamento de Administração. Pontifícia Universidade Católica do Rio de Janeiro.

Este trabalho é um estudo em Finanças Comportamentais e se propõe a compreender os níveis de aversão ao risco do gênero masculino e feminino. Através de três experimentos com loterias pareadas escalonadas, os entrevistados deveriam responder em qual linha eles mudavam de uma loteria segura com baixos ganhos para uma loteria com ganhos maiores. Conforme a probabilidade de ganho na loteria arriscada aumentava, mais indivíduos trocavam de loteria. Foi averiguado que mulheres são mais avessas ao risco do que homens, confirmando o que se observa na literatura. Além disso, foram observados o efeito certeza e o efeito reflexo descritos na Teoria do Prospecto, confirmando axiomas previstos nesta teoria.

Palavras- chave

Finanças Comportamentais; Aversão ao risco; loterias; Teoria do Prospecto

\section{Abstract}

Nogueira Margulies, Beatriz. Risk aversion by gender in scaled up lotteries. Rio de Janeiro, 2015. 32 p. Trabalho de Conclusão de Curso Departamento de Administração. Pontifícia Universidade Católica do Rio de Janeiro.

This paper is a study in Behavioral Finance that aims to understand the levels of risk aversion of males and females. Through three scaled up experiments with paired lotteries, subjects should respond in which line they changed from the safe lottery with low payoffs to the risky option with greater payoffs. As the probability of gains increased in the risky lottery, more subjects would change for this option. It was ascertained that women are more risk averse than man, confirming what was observed in the literature. In addition, it was possible to observe the certainty and reflex effects described in the Prospect Theory, confirming axioms that it predicted.

Key-words

Behavioral Finance; Risk Aversion; Lottery; Prospect Theory; Gender Preferences 


\section{Sumário}

1 O tema e o problema de estudo 1

1.1. Objetivo do estudo 2

1.2. Objetivos intermediários do estudo 2

1.3. Delimitação do estudo 2

1.4. Justificativa e relevância do estudo 2

2 Revisão de literatura 4

2.1. Hipótese dos mercados eficientes 4

2.2. Teoria das finanças comportamentais 5

2.3. Aversão à perda 6

2.4. Teoria do Prospecto 8

2.5. Loteria de Holt and Laury 10

2.6. Influência do gênero nas decisões econômicas 11

3 Métodos e procedimentos de coleta e de análise de dados do estudo 14

3.1. Etapas de coleta de dados 14

3.2. Fontes de informação selecionadas para coleta de dados no estudo15

3.3. Procedimentos e instrumentos de coleta de dados utilizados no $\begin{array}{ll}\text { estudo } & 15\end{array}$

3.4. Formas de tratamento e análise dos dados coletados para o estudo16

3.5. Limitações do Método 16

4 Apresentação e análise dos resultados $\quad 17$

4.1. Dados Gerais da Pesquisa 17

4.2. Análise dos resultados 18

4.2.1. Aversão ao risco para gênero masculino e feminino 19

4.2.2. Diferença nos ganhos relativa ao nível de aversão ao risco 23

4.2.3. Efeito dos incentivos 24

5 Conclusões e recomendações para novos estudos 26 
5.1. Conclusão da pesquisa

Anexo 1

\section{Lista de figuras}

Figura 1 Função Hipotética de valor - Kahneman e Tversky (1979, p. 279) ........ 7

Figura 2 - Exemplo de Loteria Pareada .................................................... 15

\section{Lista de Tabelas}

Tabela 1 - Percentual de escolhas seguras por gênero em cada linha.

Tabela 2 - Classificação quanto ao risco baseada nas escolhas em loterias.

Classificações adaptadas do trabalho de Holt e Laury (2002) .................. 22

Tabela 3 - Ganhos esperados por gênero em cada experimento ..................... 23

Tabela 4 - Ganhos esperados por gênero em cada experimento dividido pelo

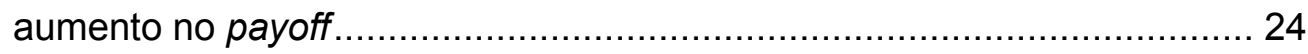

Tabela 5 - Frequência de respostas em cada linha por experimento................. 25

\section{Lista de Gráficos}


Gráfico 1 - Distribuição da amostra por gênero 17

Gráfico 2 - Proporção de escolhas seguras em cada decisão (Payoff 1x) ........ 19

Gráfico 3 - Proporção de escolhas seguras em cada decisão (Payoff 20x) ....... 19

Gráfico 4 - Proporção de escolhas seguras em cada decisão (Payoff 50x) ....... 19

Gráfico 5 - Proporção de escolhas seguras em cada decisão para diferentes

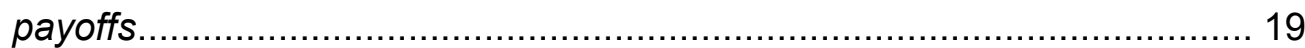

Gráfico 6 - Aversão ao risco por gênero (1x) ............................................... 21

Gráfico 7 - Aversão ao risco por gênero (20x) ............................................... 21

Gráfico 8 - Aversão ao risco por gênero (50x) ............................................... 21 


\section{0 tema e o problema de estudo}

A teoria de finanças tradicional tem como modelo central a racionalidade dos agentes econômicos, um comportamento que confirma o conceito de utilidade esperada subjetiva. O conceito de utilidade se refere ao nível de satisfação que um bem pode fornecer a um indivíduo, mensurado de forma subjetiva. Isto é, o conceito de utilidade deste bem pode variar para cada indivíduo e para diferentes contextos em que ele aparece.

Assim sendo, para a teoria tradicional de finanças os indivíduos sempre agem de forma racional, buscando a maximização de sua satisfação, otimizando a utilização de recursos que dispõe e são avessos ao risco. Mais especificamente, acredita-se que os indivíduos que atuam nos mercados financeiros são capazes de atualizar corretamente suas crenças após receberem novas informações e que suas decisões são consistentes (YOSHINAGA, 2008).

A partir desta constatação, podemos observar que o modelo tradicional não possui respostas para diversos comportamentos reais dos agentes, que não se encaixam na teoria tradicional. As teorias alternativas, portanto, vieram para complementar o pensamento clássico, e com elas, nasceu a teoria das finanças comportamentais. Ela ganhou força na década de 70 e foi apresentada por Kahneman e Tversky em 1979 como forma de tentar modelar o comportamento dito como irracional, induzindo os indivíduos a uma decisão melhor, que acarretará na redução da perda de dinheiro em situações simples do cotidiano, e consequentemente em um ganho maior (SOUZA, 2008)

Sobre este ramo, podemos observar duas questões: a primeira é sua formulação sem abandonar o pressuposto de racionalidade dos agentes e a segunda consiste na mudança de paradigma, a partir do reconhecimento de que as pessoas nem sempre se comportam racionalmente. As finanças comportamentais fundamentam-se na combinação dos conceitos oriundos da economia, das finanças, e da psicologia, com o intuito de gerar um modelo específico e criterioso do comportamento humano nos mercados financeiros, partindo do princípio que os agentes humanos estão sujeitos a determinantes comportamentais que, em muitos casos, os afastam de uma decisão centrada na racionalidade. (OLIVEIRA et al, 2005). 
O objetivo deste trabalho é apresentar um breve panorama da área de finanças comportamentais, discutindo seus fundamentos e motivações, bem como investigar a disposição do investidor em demonstrar aversão ao risco em sua tomada de decisão, ressaltando sua utilidade para a compreensão de alguns fenômenos observados na pratica.

\subsection{Objetivo do estudo}

O objetivo deste trabalho é realizar um teste para averiguar o nível de aversão ao risco dos tomadores de decisão com pequenos e altos valores e sua relação com o gênero.

\subsection{Objetivos intermediários do estudo}

Para tal, serão observados também:

- Analisar o comportamento dos indivíduos perante tomadas de decisão com riscos;

- Identificar níveis de aversão ao risco em jogos com valores pequenos e com valores maiores;

- Averiguar a relação da aversão ao risco com o gênero

\subsection{Delimitação do estudo}

O estudo estará delimitado ao universo de estudantes universitários brasileiros. Além disso, o estudo conta com incentivos monetários hipotéticos.

\subsection{Justificativa e relevância do estudo}

Por muitos anos, acreditou-se que o mercado financeiro sempre agiu de forma eficiente e racional, reagindo de acordo com as informações disponíveis no mercado e seus agentes eram considerados indivíduos racionais que visavam apenas atender a maximização de suas utilidades.

Recentemente, com o desenvolvimento das pesquisas e da capacidade de processamento dos computadores pessoais, foi possível identificar com maior regularidade contradições a hipótese de eficiência de mercado.

As limitações e contradições observadas na teoria convencional de finanças e da Hipótese dos Mercados Eficientes para explicar a formação dos 
preços dos ativos financeiros podem ser consideradas responsáveis pelo crescente prestígio acadêmico que Teoria das Finanças Comportamentais vem conquistando. Essas contradições se tornaram berço dos estudos sobre o comportamento do mercado.

Portanto, este estudo visa compreender o nível de aversão ao risco dos estudantes a partir de dois experimentos escalonados. 


\section{Revisão de literatura}

\subsection{Hipótese dos mercados eficientes}

Dado que este trabalho presume que as Finanças Comportamentais seriam uma tentativa de superar as limitações da Hipótese dos Mercados Eficientes (HME), é necessário que a análise se inicie pelo exame das suposições dessa hipótese. De acordo com Aldrighi (2005) essa hipótese pode ser definida por:

a) Concorrência perfeita: há participantes em número suficiente nos mercados de ativos financeiros para impedir que a decisão isolada de um deles afete os preços;

b) Os investidores têm preferências estáveis, formam expectativas racionais e maximizam suas utilidades esperadas;

c) As expectativas dos investidores são homogêneas, pois supõem-se que os investidores são racionais e têm igual acesso às informações e aos mercados;

d) Novas informações sobre os ativos financeiros surgem aleatoriamente, ensejando ajustes instantâneos nos portfólios dos investidores;

e) Não há fricções: os ativos são homogêneos, divisíveis e não envolvem custos de transação.

f) Os agentes são capazes de processar de maneira ótima todas as informações disponíveis

Assim sendo, o preço de qualquer ativo considera todas as informações disponíveis sobre ele, e, portanto, qualquer variação em seu preço seria devido ao surgimento de novas informações relevantes que afetou as expectativas sobre o retorno futuro e a percepção do risco e a liquidez do ativo (Milanez, 2005). Portanto, não se justificaria despender tempo e recursos para obter informações públicas com o propósito de conseguir retornos acima do retorno 
médio do mercado, uma vez que essas informações já estariam incorporadas nos preços (Fama, 1970)

Se as informações são as mesmas para qualquer investidor, não há a possibilidade de ganhos extraordinários. Apenas uma informação privilegiada sobre um ativo é o que pode vencer o mercado. De acordo com a HME, havendo uma nova informação sobre algum ativo, os preços são ajustados imediatamente de acordo com a nova informação disponibilizada. Além disso, um eventual comportamento irracional de um determinado agente, caracterizado como aleatório, seria compensado por outro indivíduo, não impactando nos preços. (LACERDA, 2007).

A partir disso, observamos que um investidor dificilmente vai ganhar do mercado "beat the market", já que a eficiência do mercado garante que os ativos sempre reflitam e incorporem todas as informações disponíveis. Entretanto, essa hipótese se mostra incompatível com diversos fenômenos financeiros reais, como "bolhas especulativas", volatilidade excessiva no preço de determinados ativos, discrepância entre o preço de mercado e valores baseados em fundamentos e prolongamento da posse de ativos perdedores.

\subsection{Teoria das finanças comportamentais}

Pessoas e tomadores de decisão são racionais e maximizadores de utilidade. Mesmo assim, estes agentes cometem erros durante o processo de tomada de decisão que podem causar variações no valor intrínseco em um ambiente livre de risco. Sabendo que a teoria tradicional de finanças não prevê esses possíveis erros dos agentes, assumimos também que ela não consegue prever possíveis variações no mercado decorrentes disto.

Nos anos 70, modelos baseados na Hipótese do Mercado Eficiente eram utilizados para especular o preço de ativos, usando os conceitos de expectativas racionais. Entretanto, observando a volatilidade nos mercados, começam os processos de indagações quanto a esses modelos. O laureado do prêmio Nobel de economia Herbert Simon, em 1976, fez um estudo onde definia alguns limites da racionalidade humana, e explicava que apesar de as pessoas tentarem agir de forma racional, elas não conseguem tomar decisões ótimas sempre, devido a alguns fatores cognitivos como restrição de tempo e limitações tanto de inteligência como de percepção. 
Neste contexto, começam a surgir mais estudos sobre economia comportamental. Em 1979 foi publicada a Teoria do Prospecto, elaborada pelos israelenses Daniel Kahneman e Amos Tversky, questionando a racionalidade dos tomadores de decisão. Este trabalho rendeu a Kahneman o prêmio Nobel de economia em 2002 pela sua contribuição no tema.

Através de diversos experimentos empíricos, os autores observaram que os resultados de seus experimentos estavam em desacordo com a Teoria da Utilidade Esperada que afirma que indivíduos tomam decisões completamente racionais, são avessas ao risco e visam maximizar a sua utilidade. A Teoria das Finanças Comportamentais considera o comportamento do investidor como razão principal para as inúmeras reações no mercado. Além disso, considera a psicologia e a sociologia como fatores determinantes no comportamento do investidor.

\subsection{Aversão à perda}

Em seu livro Positivamente Irracional (2010), o economista americano Dan Ariely descreve um teste no qual oferecia à pessoas um vale-presente de $\$ 10$ de graça ou um de $\$ 20$ pagando $\$ 7$. Contrariando a teoria de racionalidade, a maioria das pessoas optou pelo vale-presente grátis, mesmo que estivessem deixando de ganhar $\$ 3$ com a escolha. Percebemos aqui, que a decisão de não perder dinheiro, isto é, pagar os $\$ 7$, impede o indivíduo de fazer uma escolha ótima. Isso é um exemplo da aversão à perda, e do fato de o indivíduo sentir muito mais a dor da perda do que o prazer obtido por um ganho equivalente (Kahneman 1979), o que seria considerado irracional pelas teorias tradicionais de finanças.

Para Kahneman e Tversky (1979), em uma situação onde as chances de perder e de ganhar são iguais, o agente considera mais a possibilidade da perda do que a possibilidade de ganho em sua tomada de decisão, evidenciando a aversão à perda.

Ainda segundo os autores, os investidores são influenciados pelo peso dado à perda e pelo peso dado ao ganho de acordo com a probabilidade de ganhar e de perder. Um exemplo citado é, em um caso de "roleta russa", onde uma pessoa pagaria mais para reduzir o número de balas na arma de uma para 
zero, do que de diminuir de quatro para três, já que no primeiro caso esta pessoa reduziria sua chance de morte para $0 \%$, enquanto no segundo caso, reduziria a chance de $66,67 \%$ para $50 \%$, mas ainda teria boas chances de se ferir.

O gráfico abaixo serve para ilustrar este fenômeno, representando o comportamento do investidor, segundo os Kahneman e Tversky (1979) onde o peso atribuído à perda é maior do que o peso atribuído ao ganho. Abaixo, vemos uma comparação entre a curva dos ganhos e a curva das perdas. Para os ganhos, a curva é côncava e para as perdas, a curva é convexa. Isso indica que as perdas são mais sentidas pelos indivíduos do que os ganhos, evidenciando sua aversão à perda.

\section{Função Valor}

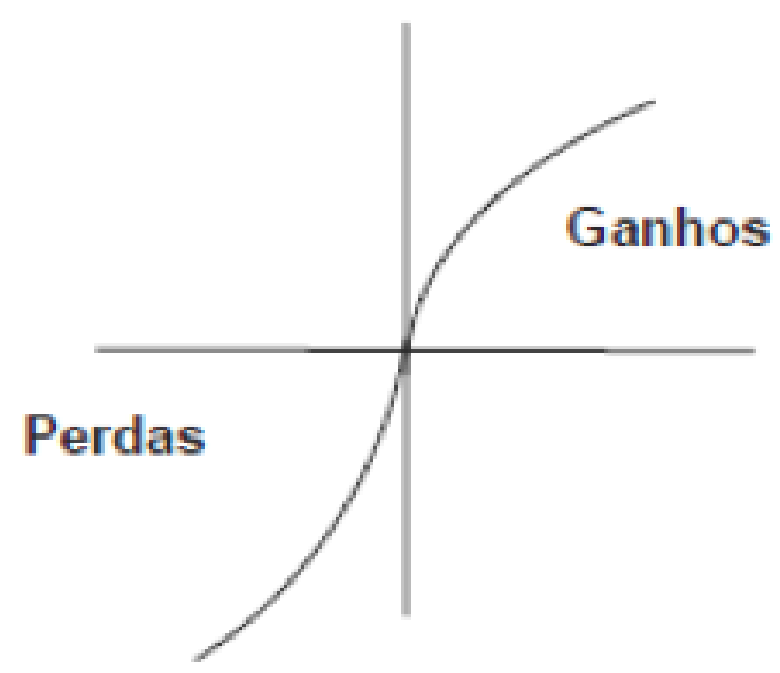

Figura 1 Função Hipotética de valor - Kahneman e Tversky (1979, p. 279)

Outra característica presente na teoria de aversão à perda é o medo do arrependimento. Segundo Shefrin (2002) arrependimento é a emoção experimentada por não ter tomado a decisão correta. Muitas vezes, os investidores evitam vender papéis com um preço inferior ao de compra, por esperarem uma alta nos preços novamente, por medo de terem prejuízo. Este medo de arrependimento faz com que estes investidores segurem por demasiado tempo o papel, deixando de fazer outros bons negócios (Statman, 2001).

De acordo com Shefrin (2002), o medo do arrependimento pode afetar as 
decisões que as pessoas fazem. Isto nos mostra o impacto que o comportamento do investidor traz às negociações no mercado financeiro. Seja em situações positivas, ao agilizar a venda de uma ação assim que demonstrar lucro, como em situações negativas, mantendo uma ação com prejuízo por muito tempo, o investidor tem seu desempenho afetado por este comportamento.

\subsection{Teoria do Prospecto}

Norteada pela crítica à HME, e a tentativa de explicar anomalias que a HME não consegue explicar, esta teoria busca analisar os efeitos dos aspectos psicológicos dos indivíduos e seu reflexo no processo de tomada de decisão financeira, com o objetivo de aperfeiçoar o modelo econômico financeiro através da incorporação de evidencias sobre a irracionalidade do investidor.

A teoria do prospecto, é apresentada como uma critica a teoria da utilidade esperada como modelo descritivo de tomada de decisão sob risco. Ela foi elaborada em 1979 no artigo "Prospect theory: An analysis of decision under risk", e apresenta um modelo alternativo buscando explicações para os processos pelos quais os impulsos sensoriais são transformados, reduzidos, elaborados, armazenados, recuperados e usados (Rogers 2007). Ela busca explicar vieses cognitivos nesse processo, clamando que o processo de tomada de decisão não é estritamente racional, e que os agentes utilizam atalhos mentais no processo. Nesta teoria, três principais efeitos relacionados à tomada de decisão foram observados, resultantes do uso de processos cognitivos enviesados. São eles o efeito certeza, reflexo e isolamento.

De acordo com os autores, pessoas atribuem pesos mais baixos à situações que são pouco prováveis, em comparação com situações que serão obtidas com certeza. Ou seja, resultados certos são geralmente excessivamente ponderados em comparação com resultados incertos. Quando indivíduos comparam um evento certo e um provável, elas tendem escolher o "evento certo" mesmo que o payoff do provável seja superior. Esta tendência, chamada de efeito certeza, contribui para a aversão ao risco em escolhas envolvendo ganhos certos, quanto tendem a prosperar e em buscar o risco em situações envolvendo perdas certas, quando a derrota é iminente.

Isto se mostra no efeito reflexo, ao descrever que a aversão ao risco no campo dos ganhos é acompanhada pela propensão ao risco no campo das 
perdas. Este conceito revela que as pessoas são avessas a perdas e não ao risco. Isto explica a tendência das pessoas buscarem ganhos seguros e perdas arriscadas, já que preferem não sofrer a dor da perda ao prazer de um ganho equivalente (Rogers 2007)

Além disso, de acordo com Tversky (1984) pessoas tendem a ignorar componentes que são compartilhados por todas as alternativas a serem escolhidas e apenas focam nos componentes que diferenciam tais alternativas. Essa tendência, denominada de efeito de isolamento, leva a escolhas inconsistentes quando a mesma decisão é apresentada em formatos diferentes. Também para Kahneman e Tversky (1979), pessoas fazem as escolhas sobre ganhos e perdas a partir de um ponto de referência, desconsiderando grande parte das características de cada opção apresentada e centralizam sua análise sobre os componentes que distinguem as opções de escolha, visando simplificar o processo de tomada de decisão.

Estas tendências apontadas acima, já mostram efeitos empíricos que invalidariam a Teoria da Utilidade Esperada como um modelo descritivo. Kahneman e Tversky explicam que a Teoria do Prospecto distingue duas fases nos processos de decisão, sendo uma fase primária de elaboração de alternativas, que consiste numa análise preliminar dos prospectos oferecidos, e que frequentemente se traduz em uma representação mais simples dos mesmos. E numa segunda fase, onde esses prospectos são avaliados e o prospecto com o valor mais alto é escolhido.

Como já mencionado, pessoas percebem resultados como ganhos e perdas e não como um estado final de riqueza ou bem estar. Este conceito de ganhos ou perda é definido em torno de um ponto de referência neutro, que geralmente corresponde à real posição do valor do ativo, em que ganhos ou perdas se traduzam no real valor recebido ou perdido. Entretanto, o lugar deste ponto de referência pode ser afetado dependendo da formulação dos prospectos oferecidos e das expectativas do tomador de decisão (Kahneman e Tversky 1979).

A função valor mostrada no gráfico da Figura 1, que visa medir a satisfação auferida por um indivíduo de um bem ou serviço, é normalmente côncava para ganhos e convexa para perdas e geralmente é mais íngreme para perdas do que para ganhos. A curva conforme a teoria da utilidade esperada, seria uma reta passando pela origem no plano cartesiano valor-ganho/perda.

A curva de risco-utilidade apresentada por Kahneman e Tversky (1979) tem como principais características a descontinuidade na origem (determinando 
a origem do sistema cartesiano como o ponto de referência na avaliação dos riscos de um investimento) e o declínio da curva após esse ponto (representando que os investidores sentem mais a dor da perda do que o prazer do ganho) (HALFELD e TORRES, 2001).

\subsection{Loteria de Holt and Laury}

Em 2002, os pesquisadores Charles Holt e Susan Laury da Universidade da Virginia escreveram o paper Risk Aversion and Incentive Effects com objetivo de inferir o grau de aversão ao risco de indivíduos. No estudo, é apresentado um menu de loterias pareadas, uma com risco maior do que a outra. São associadas probabilidades complementares para ganhos maiores e ganhos menores dentro de cada loteria, que aumentam a probabilidade de ganho maior a cada linha.

$\mathrm{Na}$ pesquisa, foi perguntado em qual linha o entrevistado mudaria da lotaria A para a loteria B. Na primeira linha, por exemplo, escolhendo a Opção A tem-se $90 \%$ de chance de ganhar US $\$ 1,60$ contra $10 \%$ de chance ganhar US\$ 2,00. Enquanto na Opção B temos $90 \%$ de chance de ganhar US\$ 0,10 e 10\% de ganhar US\$3,85.

À medida que as linhas avançam, as chances de ganhos maiores aumentam em ambas as opções, até chegar na décima linha, onde na Opção $A$ ganhavam com $100 \%$ de certeza US $\$ 2,00$ e na Opção B US\$ 3,85. Portanto, a tendência é que ao avançar na tabela, a Opção B torna-se mais interessante. Entretanto, o momento onde se troca de uma coluna para a outra, difere para cada indivíduo. Este ponto é uma medida da sua postura em relação a incerteza, refletindo sua postura em relação ao risco e podendo assim, inferir seu grau de aversão ao risco.

No experimento, o entrevistado escolhe em qual loteria quer jogar, entre duas opções. Apesar de a margem de lucro na Opção B ser muito maior que da Opção A, o limite superior desta opção encontra-se muito acima da outra, assim como seu limite inferior encontra-se muito abaixo. Com o aumento da distância em relação ao ponto de referencia, vemos que a Opção B é uma aposta muito mais elevada que a Opção $A$, isto é, seu risco é muito maior. Assim sendo, pouquíssimas pessoas escolheriam a Opção $B$, a menos que fossem tomadores de risco, ou que a chance de ganhos maiores ultrapassasse a de ganhos menores. 
Pessoas que trocam de coluna antes da linha 5 é considerado propenso ao risco, e após a linha 5 é avesso ao risco. Pessoas que trocam de coluna na linha 5 , são consideradas neutras ao risco. Elas se preocupam apenas com o ganho esperado e não com a faixa de variação, já que quando as chances são iguais para os maiores ganhos e os menores ganhos e a Opção B é quem tem um ganho esperado maior. Quem se preocupa apenas com o ganho esperado e não com a variação, é considerada avessa ao risco.

\subsection{Influência do gênero nas decisões econômicas}

De acordo com o relatório do Banco Mundial sobre Igualdade de Gênero e Desenvolvimento (2012 p. 4), a definição de "gênero se refere aos atributos sociais, comportamentais e culturais, expectativas e normas associadas a ser uma mulher ou um homem "

Quando tratamos de diferenças entre os gêneros, há uma divisão na literatura econômica e filosófica referente ao termo, visto que parte se baseia nas diferenças de oportunidades recebidas por cada um e parte se baseia na diferença das preferências e escolhas.

Mesmo seguindo a linha de que a desigualdade que enxergamos entre os gêneros provém das escolhas dos indivíduos, é válido ressaltar que essa diferença de preferência entre os gêneros é geralmente aprendida, imposta pela sociedade, e não inerente ao fato de ser homem ou mulher. Essas preferências são resultantes da cultura que faz com que homens e mulheres busquem atender a expectativas sociais. A partir do momento que essa distinção de atitudes é internalizada, elas tendem a perpetuar essa desigualdade.

De acordo com o relatório, tratando-se de preferências, necessidades e restrições, estas podem diferir sistematicamente entre homens e mulheres, refletindo tanto fatores biológicos quanto comportamentos sociais "aprendidos".

Colarelli, Spranger e Hechanova (2006) apresentam questões biológicas como possíveis influências no perfil de risco. Por exemplo, o alto índice de alguns hormônios em homens como testosterona e cortisol pode levá-los a atitudes mais competitivas, que seriam a razão de seu perfil mais agressivo na tomada de risco frente às mulheres.

A diferença de percepção entre os gêneros quanto ao risco, entretanto, vai muito além de uma questão biológica. O comportamento na tomada de decisão é 
baseado em toda uma cultura sobre o papel do indivíduo na sociedade. Em 2004, Croson e Gneezy apresentaram seu trabalho Gender Differences in Preferences no qual fizeram uma extensa revisão bibliográfica sobre o tema tentando fornecer explicações para a diferença de ganhos entre o homens e mulheres no mercado em geral.

Os autores revisaram dez trabalhos sobre mensuração de tolerância ao risco em loterias como os de Holt e Laury (2002), Dohmen et al (2005), Eckel e Grossman (2002) e apontou que em todos os resultados as mulheres se mostraram mais avessas ao risco que os homens, sendo em situações de perda ou de ganho.

Mesmo assim, é importante enfatizar que esses experimentos foram realizados em sua maioria em países desenvolvidos e ocidentais que representam sociedades patriarcais. Portanto, é quase impossível extrair esses fatores sociais para a pesquisa, e saber até que ponto as decisões de homens e mulheres são inerentes ao ser e não ao papel na sociedade, até porque as descobertas dessas pesquisas seriam utilizadas em sociedades similares, tornando essa questão não tão relevante.

Entretanto, os pesquisadores Uri Gneezy, Kenneth Leonard e John List (2009) apresentaram uma das pesquisas mais interessantes sobre as diferenças de gênero quanto a competitividade. Eles visitaram a sociedade Masaai na Tanzânia e Khasi na Índia, que como diferença tem o fato de a sociedade Masaai ser tipicamente patriarcal e Khasi ser matrilinear. Na sociedade Masaai os homens optam pelo ambiente competitivo duas vezes mais que as mulheres, resultado similar ao encontrado em pesquisas feitas nos países ocidentais. Ao mesmo tempo, na sociedade Khasi as mulheres buscam a competitividade mais frequentemente que os homens Khasi e se mostraram mais competitivas inclusive que os homens Masaai. Esses resultados nos fornecem evidências sobre os fundamentos da hipótese das diferenças das escolhas de cada gênero em ambientes competitivos.

Vale ressaltar que ao se referir a competitividade os autores remetem também a questão da aversão ao risco, já que ambos os comportamentos estão diretamente relacionados às preferências dos indivíduos. Essa pesquisa, assim como muitas outras baseadas em economia experimental não é perfeita e tem inúmeros fatores culturais que também poderiam invalidá-la. Mesmo assim representa um bom caminho para tentar compreender a real influência do gênero como uma identidade, na tomada de decisão. 
Portanto, por trás das diferenças de gênero há questões emocionais, sociais, biológicas e culturais que influenciam o resultado das pesquisas. Em suma, a literatura indica que o gênero feminino apresenta maior propensão ao risco, entretanto, não foi capaz de isolar quais questões relativas ao gênero são responsáveis por esses resultados. 


\section{Métodos e procedimentos de coleta e de análise de dados do estudo}

\subsection{Etapas de coleta de dados}

O questionário utilizado é uma adaptação da pesquisa feita no trabalho de Charles Holt e Susan Laury de 2002, Risk Aversion and Incentive Effects (Anexo A).

Foram enviados questionários online, para 105 alunos através da plataforma Qualtrics. Em sua pesquisa, os autores examinaram os efeitos de incentivos em entrevistados e sua aversão ao risco, através de questionário com uma lista de dez pares de loterias com recompensas monetárias reais e hipotéticas e com valores em escala.

Entretanto, os valores dos incentivos dos autores foram convertidos para reais para se adequar mais à realidade da amostra, estudantes brasileiros. Para isso, os valores foram multiplicados pela taxa de câmbio média praticada em 2015, até o dia 10 de setembro.

Os estudantes foram apresentados a três experimentos. O primeiro tinha uma lista de dez opções de loteria (em pares), com possibilidade de baixos ganhos, valores menores. Num segundo momento, foi apresentado aos entrevistados outro menu de loterias, dessa vez com payoffs hipotéticos numa escala 20x a do exercício anterior. Por fim, foram apresentados a uma loteria em escala 50x. Com isso, visamos compreender se o nível de aversão ao risco aumenta, conforme o payoff também cresce. 
$\underline{1 x}$

Opção A

$1 / 10$ de $\mathrm{R} \$ 6,34$ e $9 / 10$ de 5,07
Opção B

$1 / 10$ de $R \$ 12,20$ e $9 / 10$ de 0,32

\section{Opção A}

$\underline{20 x}$

\section{Opção B}

$1 / 10$ de $R \$ 243,95$ e $9 / 10$ de 6,34

$\underline{50 x}$

Opção A

$1 / 10$ de $\mathrm{R} \$ 316,81$ e $9 / 10$ de 253,45
Opção A

$1 / 10$ de $\mathrm{R} \$ 609,86$ e $9 / 10$ de 15,84

Figura 2 - Exemplo de Loteria Pareada

Além disso, os respondentes foram questionados sobre o gênero, para saber se haveria variação significativa nas respostas de acordo com ele.

\subsection{Fontes de informação selecionadas para coleta de dados no estudo}

Como o estudo visa compreender apenas o comportamento de estudantes brasileiros quanto ao risco, o estudo foi restrito a este grupo.

\subsection{Procedimentos e instrumentos de coleta de dados utilizados no estudo}

Os dados foram coletados através de questionário online, elaborado na plataforma Qualtrics. O sistema foi escolhido por facilitar a coleta de dados por múltiplos respondentes, de forma a enriquecer a pesquisa. Além disso, ele permite acompanhamento das respostas em tempo real, e oferece relatórios padronizados, gráficos e estatísticas e possibilidade de exportação para o Excel ou SPSS.

A amostra contou com 105 alunos que deveriam responder três experimentos com base nas loterias apresentadas, em qual linha eles trocariam de uma para outra, apontando assim, seu nível de aversão/propensão ao risco. 


\subsection{Formas de tratamento e análise dos dados coletados para o estudo}

Os dados coletados neste trabalho foram tratados de forma quantitativa. Foram apresentados a um questionário para compreender seus níveis de aversão ao risco quando confrontados com a escolha entre duas loterias com risco maior ou menor.

A partir disso, foram realizados testes para correlacionar o gênero dos entrevistados com a aversão à perda, e tentar compreender se seu comportamento é alterado conforme o risco apresentado. Para explorar o efeito da possibilidade de maiores ganhos, os entrevistados tiveram que responder a três questões que apresentavam o mesmo payoff, apenas com valor escalonado.

\subsection{Limitações do Método}

Devido à falta de financiamento, não foi possível conceder um incentivo monetário direto aos participantes. De todo modo, vale ressaltar que na pesquisa de Kahneman e Tversky de 1992 "Advances in Prospect Theory: Cumulative Representation of Uncertainty" que avalia efeitos similares, também não foram utilizados incentivos monetários. Em seu estudo, os autores afirmam que em sua experiência com pesquisas em relação a tomadas de decisão, eles não enxergavam muita diferente entre resultados de pesquisas com incentivos monetários reais ou não. Esta ideia também é reforçada por Camerer, que em 1989 investigou efeitos entre jogadores que receberam ou não o incentivo e não encontrou diferenças significativas nas respostas. 


\section{Apresentação e análise dos resultados}

\subsection{Dados Gerais da Pesquisa}

Inicialmente é importante compreender o perfil da amostra dos entrevistados. O teste foi feito com 105 alunos de graduação da PUC-Rio, IMBEC, UFRJ, FGV-SP e UFBA sendo 60 do gênero masculino e 45 do gênero feminino.

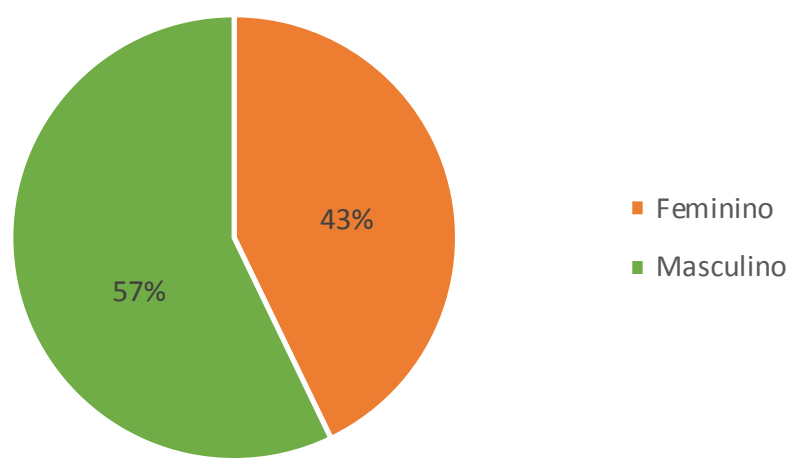

Gráfico 1 - Distribuição da amostra por gênero

Após a aplicação dos questionários, os dados obtidos foram tabulados e logo após foi iniciada a análise, na qual procuramos identificar nas respostas indicadores de como os entrevistados se comportam em relação à aversão ao risco.

Inicialmente, a análise foi feita segmentando os entrevistados por gênero. Em um segundo momento, foram analisados todos os entrevistados como um só grupo. As análises separadas tiveram como o objetivo analisar mais especificamente o comportamento de homens e mulheres compreender a magnitude da diferença de suas respostas versus uma análise mais geral, visando compreender melhor os efeitos dos incentivos.

O número de escolhas seguras de um respondente pode ser utilizado como um indicador da sua aversão ao risco, e não este número não muda conforme os payoff são escalonados.

A aversão ao risco dos entrevistados foi mensurada e estruturada em gráficos para a melhor demonstração. A análise de dados foi feita mensurando 
quantas vezes o indivíduo preferia a opção segura $A$ antes de trocar para opção de maior risco, $\mathrm{B}$.

Para isso, observou-se o percentual de pessoas que mantinha escolhas seguras até cada linha, como demonstrado abaixo na tabela 1. A partir disso, foram observadas as frequências acumuladas e subtraídas do todo, para a elaboração dos gráficos apresentados.

\subsection{Análise dos resultados}

A partir dos resultados encontrados foram elaborados gráficos para indicar os níveis de aversão ao risco dos respondentes nos diferentes testes feitos com valores hipotéticos. Assumindo que a Opção $A$ é menos arriscada que a Opção $\mathrm{B}$, o número de escolhas da Opção $\mathrm{A}$ antes de trocar para a $\mathrm{B}$ será o indicador utilizado para analisar a aversão ao risco.

Nos gráficos 2, 3 e 4 abaixo, o eixo horizontal representa a linha de decisão e o eixo vertical indica a porcentagem de indivíduos que escolheram a Opção A até certa linha. A linha pontilhada neles indica a resposta sob hipótese da neutralidade ao risco, na qual o indivíduo escolhe a opção $A$ nas quatro primeiras decisões, trocando para a B nas outras decisões. Se a resposta dos entrevistados seguisse a tendência dessa linha, saberíamos que todos são neutros ao risco.

Linhas posicionadas à direita da linha tracejada, que corresponde a previsão de neutralidade ao risco, indicam uma tendência de aversão ao risco entre esses indivíduos. Isto é, para tais pontos existem mais indivíduos optando pelas opções seguras do que pelas opções arriscadas.

Linhas à esquerda (ou para dentro) da linha tracejada indicam o oposto, ou seja, em determinado ponto os indivíduos têm maior propensão ao risco.

Os gráficos 2, 3 e 4 abaixo mostram proporcionalmente percentual dos indivíduos que escolheu pelo menos $x$ respostas seguras, em contraste com a linha que define a hipótese de escolha neutra ao risco, dada pela linha pontilhada preta. Estes resultados mostram uma tendência a aversão ao risco dentre os entrevistados, dado que se situam à direita da predição neutra ao risco. 


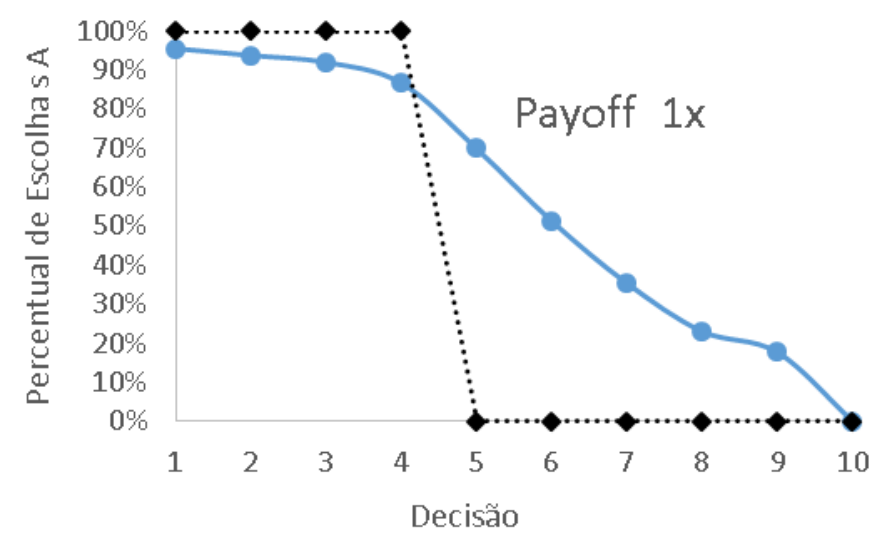

Gráfico 2 - Proporção de escolhas seguras em cada decisão (Payoff 1x)

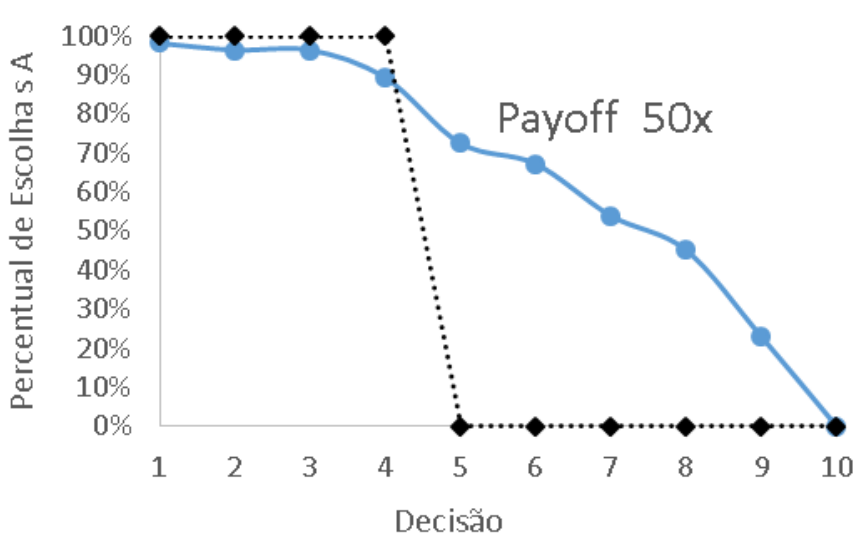

Gráfico 4 - Proporção de escolhas seguras em cada decisão (Payoff 50x)

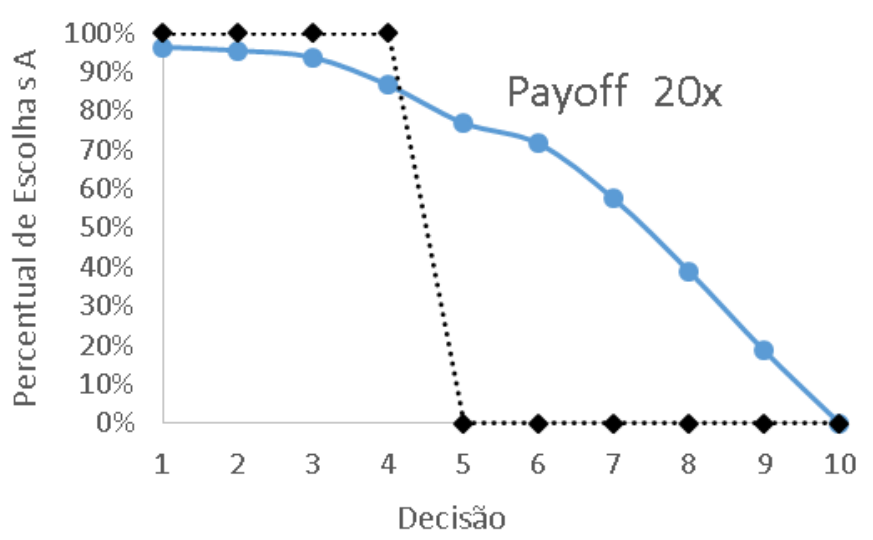

Gráfico 3 - Proporção de escolhas seguras em cada decisão (Payoff 20x)

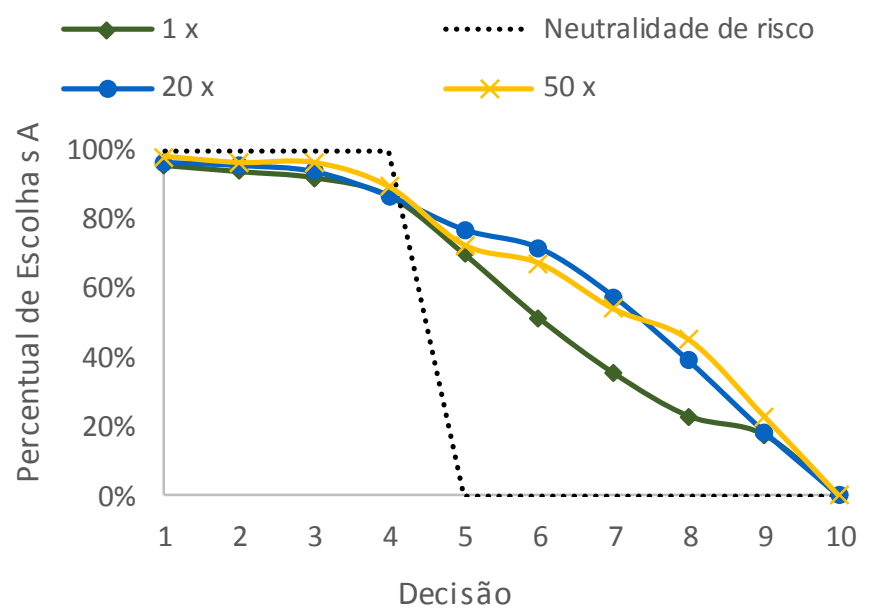

Gráfico 5 - Proporção de escolhas seguras em cada decisão para diferentes payoffs

\subsubsection{Aversão ao risco para gênero masculino e feminino}

Considerando a premissa de que a loteria A é uma opção mais segura, com menos riscos que a opção $B$, o número de escolhas $A$ de cada participante também será utilizado para indicar o nível de aversão ao risco do indivíduo neste caso.

A tabela abaixo mostra o percentual de cada gênero referente às escolhas A para cada linha. 
HOMENS

\begin{tabular}{|c|c|c|c|}
\hline \\
\hline Linhas & $\underline{1 x}$ & $\underline{20 x}$ & $\underline{50 x}$ \\
\hline 1 & $92 \%$ & $98 \%$ & $98 \%$ \\
\hline 2 & $92 \%$ & $98 \%$ & $98 \%$ \\
\hline 3 & $90 \%$ & $97 \%$ & $98 \%$ \\
\hline 4 & $82 \%$ & $90 \%$ & $90 \%$ \\
\hline 5 & $63 \%$ & $78 \%$ & $75 \%$ \\
\hline 6 & $43 \%$ & $70 \%$ & $70 \%$ \\
\hline 7 & $30 \%$ & $50 \%$ & $57 \%$ \\
\hline 8 & $18 \%$ & $33 \%$ & $48 \%$ \\
\hline 9 & $12 \%$ & $15 \%$ & $22 \%$ \\
\hline 10 & $0 \%$ & $0 \%$ & $0 \%$ \\
\hline
\end{tabular}

MULHERES

\begin{tabular}{|c|c|c|c|}
\hline Linhas & $\underline{1 x}$ & $20 x$ & $50 x$ \\
\hline 1 & $100 \%$ & $96 \%$ & $98 \%$ \\
\hline 2 & $98 \%$ & $93 \%$ & $93 \%$ \\
\hline 3 & $98 \%$ & $91 \%$ & $93 \%$ \\
\hline 4 & $98 \%$ & $82 \%$ & $91 \%$ \\
\hline 5 & $82 \%$ & $78 \%$ & $71 \%$ \\
\hline 6 & $64 \%$ & $76 \%$ & $64 \%$ \\
\hline 7 & $44 \%$ & $67 \%$ & $51 \%$ \\
\hline 8 & $33 \%$ & $44 \%$ & $40 \%$ \\
\hline 9 & $28 \%$ & $22 \%$ & $24 \%$ \\
\hline 10 & $1 \%$ & $0 \%$ & $0 \%$ \\
\hline
\end{tabular}

Tabela 1 - Percentual de escolhas seguras por gênero em cada linha

O efeito dos incentivos será analisado mais especificamente no tópico abaixo. Entretanto, nos gráficos 6,7 e 8 já podemos perceber a diferença no perfil de risco entre homens e mulheres.

Nas primeiras questões com incentivos pequenos, é fácil perceber que a linha representando o gênero feminino está à direita da linha de neutralidade de risco de forma mais pronunciada que a masculina. Isso nos indica a maior aversão ao risco das mulheres em situações de ganhos pequenos e hipotéticos.

Conforme o payoff era aumentado, a diferença nas repostas entre os gêneros começa a mudar. Podemos observar nos gráficos 7 e 8 que pelo menos $8 \%$ das mulheres se comportou de forma mais propensa ao risco do que os homens no início, e que todo o resto se mostrou mais avesso. Pode ser entendido daí, que as mulheres propensas ao risco aceitam tomar um risco maior do que os homens propensos e que mulheres se tornam menos avessas ao risco conforme o ganho esperado aumenta. 
Proporção de decisões seguras em cada escolha (1x)

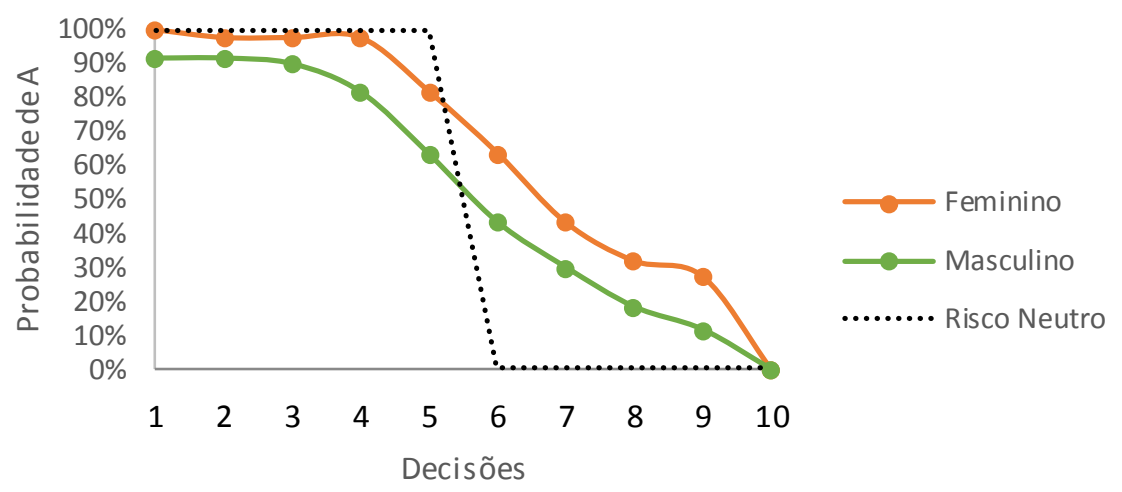

Gráfico 6 - Aversão ao risco por gênero (1x)

Proporção de decisões seguras em cada decisão (20x)

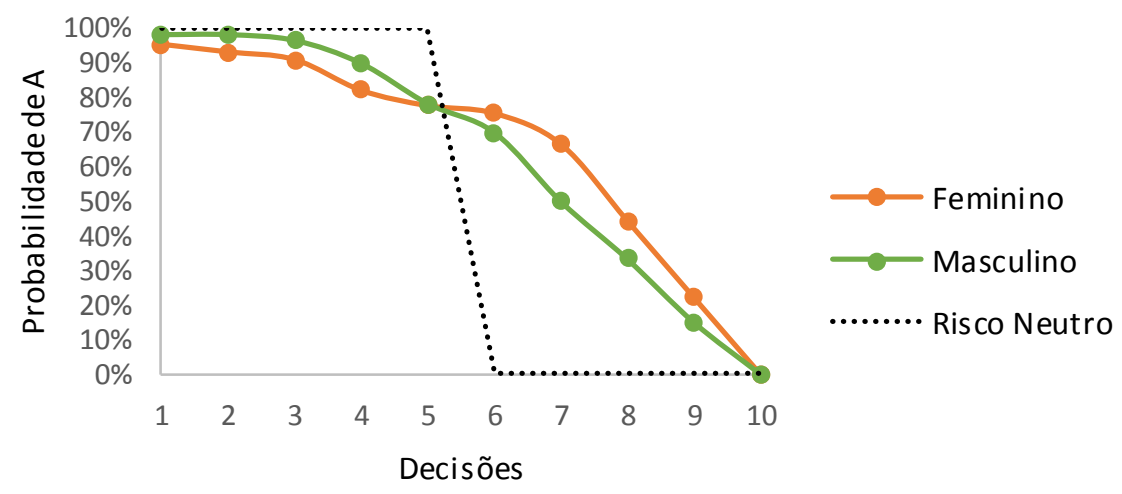

Gráfico 7 - Aversão ao risco por gênero (20x)

Proporção de decisões seguras em cada decisão (50x)

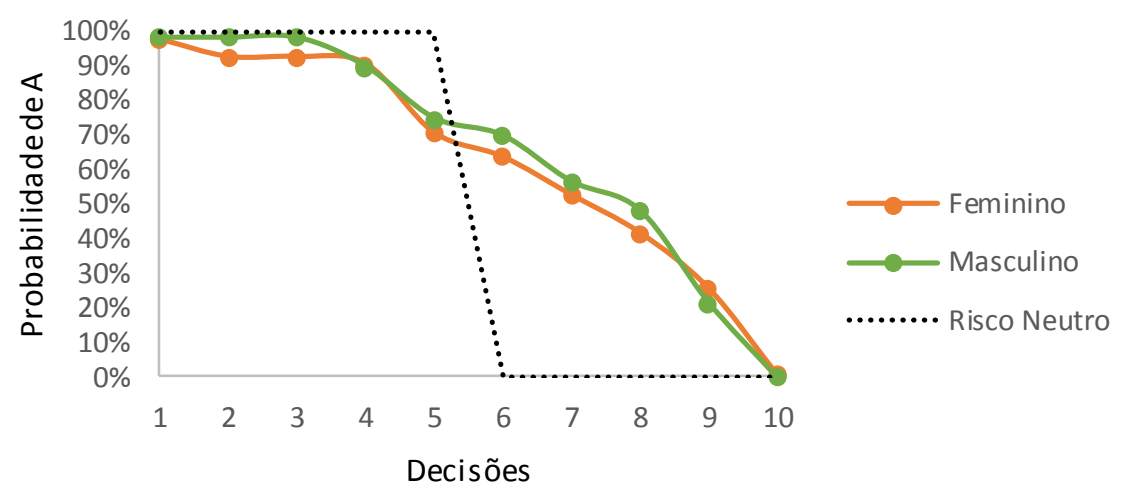

Gráfico 8 - Aversão ao risco por gênero (50x) 
Mesmo com recompensas baixas e hipotéticas, notou-se um nível considerável de aversão ao risco entre os participantes. Para analisar a diferença entre as proporções de indivíduos avessos ao risco em cada grupo, consideramos indivíduos avessos ao risco aqueles que trocaram para a opção $B$ após a linha 6 , sobre o total.

Desta forma, observando a média das respostas nos casos com os 3 diferentes payoffs, sabemos que pelo menos $77 \%$ das mulheres se comportou de forma avessa ao risco, contra $72 \%$ dos homens.

É interessante reparar na tabela 1 a maior concentração de respostas das mulheres nas linhas finais e dos homens mais dispersas, indicando um grupo significativo de mulheres avessas ao risco. Se formos observar o comportamento apenas das pessoas com este perfil, isto é, aqueles que precisam de $90 \%$ de certeza de um ganho para buscar seu resultado maior, veremos $42 \%$ das mulheres sendo extremamente avessas ao risco, contra $34 \%$ dos homens com este perfil, que Holt e Laury (2002) definem como "stay in bed".

$\mathrm{Na}$ tabela 2 observamos a frequência de escolhas seguras para cada grupo de indivíduos, fazendo a média de suas respostas nos três experimentos. Ou seja, que percentual de cada grupo mudou de resposta em cada linha. As 9 classificações quanto ao perfil de risco indicadas na tabela 2 foram traduzidas livremente da obra de Holt e Laury (2002).

\begin{tabular}{cccc}
\hline $\begin{array}{c}\text { Qtde. de } \\
\text { escolhas } \\
\text { seguras }\end{array}$ & $\begin{array}{c}\text { Classificação quanto ao } \\
\text { risco }\end{array}$ & Homens & Mulheres \\
\hline \hline $\mathbf{0 - 1}$ & Altamente propenso ao risco & $4 \%$ & $2 \%$ \\
$\mathbf{2}$ & Bastante propenso ao risco & $0 \%$ & $3 \%$ \\
$\mathbf{3}$ & Propenso ao risco & $1 \%$ & $1 \%$ \\
$\mathbf{4}$ & Neutro ao risco & $8 \%$ & $2 \%$ \\
$\mathbf{5}$ & Levemente avesso ao risco & $14 \%$ & $14 \%$ \\
$\mathbf{6}$ & Avesso ao risco & $11 \%$ & $9 \%$ \\
$\mathbf{7}$ & Bastante avesso ao risco & $16 \%$ & $11 \%$ \\
$\mathbf{8}$ & Altamente avesso ao risco & $12 \%$ & $15 \%$ \\
$\mathbf{9 - 1 0}$ & Fique em casa & $34 \%$ & $42 \%$ \\
\hline
\end{tabular}

Tabela 2 - Classificação quanto ao risco baseada nas escolhas em loterias. Classificações adaptadas do trabalho de Holt e Laury (2002) 


\subsubsection{Diferença nos ganhos relativa ao nível de aversão ao risco}

Um ponto que deve ser observado na pesquisa é a diferença nos ganhos esperados dos homens e das mulheres, dependendo de suas respostas. Cruzando o percentual de respondentes de cada linha com o ganho esperado desta resposta, podemos descobrir o ganho médio, e o maior e menor ganho dos participantes de acordo com o gênero, e em cada experimento.

\begin{tabular}{|c||cc||cc||cc||}
\multicolumn{1}{l||}{} & \multicolumn{2}{c||}{ Ganhos Médios } & \multicolumn{2}{c||}{ Menor Ganho } & \multicolumn{2}{c||}{ Maior Ganho } \\
\multicolumn{1}{c||}{} & Homem & Mulher & Homem & Mulher & Homem & Mulher \\
1x & $-R \$ 0,18$ & $-R \$ 0,31$ & $-R \$ 0,68$ & $-R \$ 1,58$ & $R \$ 0,31$ & $R \$ 0,05$ \\
20x & $-R \$ 5,99$ & $-R \$ 6,39$ & $-R \$ 17,60$ & $-R \$ 26,05$ & $R \$ 1,23$ & $R \$ 3,28$ \\
50x & $-R \$ 16,39$ & $-R \$ 14,80$ & $-R \$ 64,00$ & $-R \$ 71,63$ & $R \$ 3,08$ & $R \$ 5,84$
\end{tabular}

Tabela 3 - Ganhos esperados por gênero em cada experimento

Observando a tabela 3 fica evidente que o nível de tolerância ao risco pode implicar em ganhos maiores e menores aos indivíduos. Com incentivos menores (1x) as mulheres ganharam em média $42 \%$ menos do que os homens e seu maior ganho correspondeu a apenas $16 \%$ do valor do maior ganho dos homens. Já no caso de maiores payoffs, as mulheres ganharam em média mais do que os homens e seu maior ganho foi mais que o dobro do que o dos homens.

$\mathrm{Na}$ tabela 4 abaixo, podemos observar a mesma tabela 3 normalizada, ou seja, com os ganhos esperados divididos pelo tamanho do aumento no payoff do experimento inicial (1x). O objetivo é de que pudéssemos compará-lo com a resposta inicial, e entender melhor como a variação do estímulo ao indivíduo pode alterar seu ganho.

Nitidamente, a variabilidade das respostas das mulheres foi maior, visto que elas em todos os casos obtiveram o menor ganho de todos, e no segundo e terceiro experimento obtiveram o maior ganho. É bastante claro também o papel dos estímulos nos indivíduos. Confrontadas com a possibilidade de maiores ganhos, as mulheres rapidamente mudam seu perfil de risco, conferindo a elas ganhos maiores que os homens, como pode ser observado na terceira linha da tabela 4. 


\begin{tabular}{|l||cc||cc||cc||}
\multicolumn{1}{c||}{} & \multicolumn{2}{c||}{ Ganhos Médios } & \multicolumn{2}{c||}{ Menor Ganho } & \multicolumn{2}{c||}{ Maior Ganho } \\
\multicolumn{1}{c||}{} & Homem & Mulher & Homem & Mulher & Homem & Mulher \\
$\mathbf{1 x}$ & $-\mathrm{R} \$ 0,18$ & $-\mathrm{R} \$ 0,31$ & $-\mathrm{R} \$ 0,68$ & $-\mathrm{R} \$ 1,58$ & $\mathrm{R} \$ 0,31$ & $\mathrm{R} \$ 0,05$ \\
$\mathbf{2 0 x}$ & $-\mathrm{R} \$ 0,30$ & $-\mathrm{R} \$ 0,32$ & $-\mathrm{R} \$ 0,88$ & $-\mathrm{R} \$ 1,30$ & $\mathrm{R} \$ 0,06$ & $\mathrm{R} \$ 0,16$ \\
$\mathbf{5 0 x}$ & $-\mathrm{R} \$ 0,33$ & $-\mathrm{R} \$ 0,30$ & $-\mathrm{R} \$ 1,28$ & $-\mathrm{R} \$ 1,43$ & $\mathrm{R} \$ 0,06$ & $\mathrm{R} \$ 0,12$
\end{tabular}

Tabela 4 - Ganhos esperados por gênero em cada experimento dividido pelo aumento no payoff

É válido mencionar que não é a maior propensão ao risco que gera os melhores resultados, e sim, a racionalidade do agente. Para a Teoria da Utilidade Esperada os agentes seriam racionais a todo tempo visando maximizar sua utilidade, seus ganhos nas loterias. Neste caso, diferentemente do mundo real, rapidamente os entrevistados conseguiriam descobrir a linha na qual teriam seus ganhos maximizados e mesmo assim não o fizeram.

Fatores como limitação de tempo e inteligência, e aversão ao risco influenciaram nas decisões desses indivíduos, fazendo com que estes não escolhessem uma linha que maximizasse sua utilidade. Essas anomalias nas escolhas das pessoas que podem ser explicadas por inúmeros fatores cognitivos são responsáveis pelas "anomalias" e a imprevisibilidade no mercado.

\subsubsection{Efeito dos incentivos}

Em todos os experimentos feitos, a maioria dos entrevistados escolheu opções de pouco risco enquanto a probabilidade de um alto ganho era pequena, entretanto, trocaram para a Opção B após a linha 6, quando suas chances passam a aumentar de forma relevante. Mesmo assim, é visível o efeito dos incentivos nas escolhas dos respondentes. No primeiro par de loterias com incentivos $1 \mathrm{x}, 87 \%$ dos entrevistados fizeram pelo menos 4 escolhas seguras antes de mudar para a loteria de maior risco. Com incentivos $20 x$ a proporção foi idêntica $87 \%$ em $50 x$ foi de $89 \%$. Em todos os casos a grande maioria se comportou de forma avessa ao risco. 


\begin{tabular}{|cccc|}
\hline Linhas & $\underline{\mathbf{1 x}}$ & $\underline{\mathbf{2 0 x}}$ & $\underline{\mathbf{5 0 x}}$ \\
$\mathbf{1}$ & $4 \%$ & $4 \%$ & $\mathbf{2 \%}$ \\
$\mathbf{2}$ & $2 \%$ & $1 \%$ & $2 \%$ \\
$\mathbf{3}$ & $2 \%$ & $2 \%$ & $0 \%$ \\
$\mathbf{4}$ & $5 \%$ & $7 \%$ & $7 \%$ \\
$\mathbf{5}$ & $17 \%$ & $10 \%$ & $17 \%$ \\
$\mathbf{6}$ & $19 \%$ & $5 \%$ & $5 \%$ \\
$\mathbf{7}$ & $16 \%$ & $14 \%$ & $13 \%$ \\
$\mathbf{8}$ & $12 \%$ & $19 \%$ & $9 \%$ \\
$\mathbf{9}$ & $5 \%$ & $20 \%$ & $22 \%$ \\
$\mathbf{1 0}$ & $18 \%$ & $19 \%$ & $23 \%$ \\
\hline
\end{tabular}

Tabela 5 - Frequência de respostas em cada linha por experimento

A mesma tabela para averiguar os níveis de aversão ao risco entre os gêneros foi utilizada para averiguar os níveis de aversão ao risco para os indivíduos de acordo com o valor a ser recebido.

De acordo com Holt e Laury (2002), se todos os payoffs são ampliados por uma constante $\mathrm{k}$, então esta constante pode nos dar a função de aversão relativa constante ao risco (CRRA). Neste caso, o número de escolhas certas não seria afetado por alterações na escala de pagamento. Uma mudança nos padrões de escolha conforme os pagamentos são ajustados para cima é inconsistente com a aversão relativa constante ao risco (CRRA).

\begin{tabular}{ccccccc}
\hline $\begin{array}{c}\text { Qtde. de } \\
\text { escolhas } \\
\text { seguras }\end{array}$ & $\begin{array}{c}\text { Classificação quanto ao } \\
\text { risco }\end{array}$ & $\underline{\mathbf{1 x}}$ & $\underline{\mathbf{2 0 x}}$ & $\underline{\mathbf{5 0 x}}$ & $\underline{\text { Média }}$ \\
\hline \hline $\mathbf{0 - 1}$ & Altamente propenso ao risco & $4 \%$ & $3 \%$ & $\mathbf{2} \%$ & $3 \%$ \\
$\mathbf{2}$ & Bastante propenso ao risco & $1 \%$ & $1 \%$ & $\mathbf{2} \%$ & $\mathbf{2} \%$ \\
$\mathbf{3}$ & Propenso ao risco & $1 \%$ & $\mathbf{2 \%}$ & $0 \%$ & $1 \%$ \\
$\mathbf{4}$ & Neutro ao risco & $4 \%$ & $7 \%$ & $4 \%$ & $5 \%$ \\
$\mathbf{5}$ & Levemente avesso ao risco & $16 \%$ & $8 \%$ & $18 \%$ & $14 \%$ \\
$\mathbf{6}$ & Avesso ao risco & $19 \%$ & $5 \%$ & $6 \%$ & $10 \%$ \\
$\mathbf{7}$ & Muito avesso ao risco & $17 \%$ & $14 \%$ & $10 \%$ & $14 \%$ \\
$\mathbf{8}$ & Altamente avesso ao risco & $12 \%$ & $18 \%$ & $10 \%$ & $14 \%$ \\
$\mathbf{9 - 1 0}$ & Fique em casa & $26 \%$ & $41 \%$ & $47 \%$ & $38 \%$ \\
\hline
\end{tabular}




\section{Conclusões e recomendações para novos estudos}

\subsection{Conclusão da pesquisa}

Conforme proposto neste trabalho, relacionando conceitos e teorias baseadas nas Finanças Comportamentais, e aplicando uma pesquisa adaptada do trabalho de Holt e Laury (2002) foram obtidos resultados que evidenciaram que homens e mulheres nem sempre se comportam da mesma forma quando tomam risco. Observando os resultados apresentados no capítulo quatro, podemos identificar diferentes níveis de tolerância ao risco para os participantes.

Os resultados apresentam pontos que se encaixam na Teoria da Utilidade Esperada (TUE) ao ponto em que também se enxerga sua relação com a Teoria do Prospecto. Quanto a TUE, podemos observar que $14 \%$ dos indivíduos apresentou racionalidade na tomada de decisão sob risco, tentando maximizar a sua utilidade em decisões de risco. Mesmo assim, $86 \%$ dos indivíduos tomou sua decisão baseados em preferências e aspectos emocionais ou cognitivos. Desses, apenas $13 \%$ se mostrou propenso a tomar riscos ao ponto que a grande maioria, $73 \%$ se mostrou avesso ao risco, evidenciando alguns dos efeitos observados na Teoria do Prospecto.

Podemos observar o efeito certeza ao ponto que temos mais de dois terços dos entrevistados mudando de loteria após a linha 6, mostrando sua tendência de aversão ao risco. Essas pessoas claramente não buscavam resultados, visto que ponderaram mais o desejo por ganhos certos do que por um resultado incerto, fazendo com que escolhessem os eventos certos mesmo que houvesse uma decisão mais arriscada que gerasse um payoff superior para elas.

O efeito reflexo aparece nos gráficos 5,6,7 que mostram que os indivíduos são propensos ao risco no campo das perdas (até a linha 4) e avessos ao risco no campo dos ganhos. Este efeito aparece com mais destaque nas escolhas das entrevistadas do gênero feminino no segundo experimento (20x). No gráfico 6 , as linhas representando a proporção de respondentes de $A$ estão à esquerda da linha de neutralidade de risco até a decisão 5 , quando passa para a direita. Isto confirmaria a hipótese de que pessoas são avessas a perdas e não ao risco. 
As conclusões pesquisas confirmam os resultados de Croson e Gneezy (2004), Araújo e Tibúrcio Silva (2006), Weber (2008) e Gava e Vieira (2008), apontando a influência do gênero nas decisões tomadas, visto que o gênero feminino demonstrou mais aversão ao risco que os participantes do gênero masculino.

Vale ressaltar a mudança na relação quanto ao risco das mulheres conforme os payoffs aumentaram. Mesmo que se mostrassem nitidamente mais avessas ao risco que os homens nos primeiros experimentos, é notável uma mudança de comportamento no $3^{\circ}$ experimento, com os valores originais escalonados $(50 \mathrm{x})$.

\subsection{Sugestões e recomendações para novos estudos}

A tentativa de criar ou modificar teorias econômicas tem se tornado muito importante atualmente, dada à crescente vontade de aplicar teorias que se encaixem cada vez melhor no mundo real. Muitas pesquisas econômicas se baseiam em axiomas que não representam bem a realidade, podendo apresentar resultados inesperados quando confrontadas com o mundo real.

Para isso, o homem não deve ser enxergado estritamente como o homo economicus descrito por Adam Smith (1776), como um indivíduo egoísta que busca apenas maximizar sua utilidade em suas escolhas. Cada vez mais a economia tem se permitido influenciar por outras ciências sociais para conseguir realizar previsões com mais autencidade.

Esse trabalho é uma tentativa de mostrar que agentes não são sempre racionais e que homens e mulheres têm comportamentos distintos em relação ao risco. Ambas as hipóteses puderam ser provadas. Mesmo assim, devido à falta de incentivos monetários reais e principalmente ao modo pelo qual a pesquisa foi aplicada (por questionários online nos quais os participantes demonstraram restrição de tempo e dificuldade em entender as propostas da pesquisa) alguns resultados podem ter apresentado resposta enviesada.

Desta forma, uma proposta para futuros estudos relacionados à economia experimental seria a realização de testes com retornos reais e retornos hipotéticos, de forma que pudéssemos comparar o efeito dos incentivos monetários reais nos indivíduos.

Outra sugestão seria a realização do teste com grupos de homens e mulheres de faixa etária e com características socioeconômicas distintas, visto 
que a pesquisa foi feita apenas com alunos de graduação com características muito semelhantes, o que pode ter atenuado as diferenças de perfil entre os gêneros. Uma pesquisa futura poderia tentar extrair os fatores que geram esse resultado, que podem ser fruto da amostra com estudantes de classe média que tem expectativas e formação parecida.

Quanto as pesquisas relacionadas à desigualdade entre os gêneros, poderia ser interessante tentar inferir o quando a riqueza das pessoas pode ser alterada conforme seu nível de aversão ao risco e o quanto isso pode ser um fator que contribui para a desigualdade entre os gêneros, visto que estes têm perfis de risco distintos. 


\section{Referências Bibliográficas}

ALDRIGHI, Dante Mendes; MILANEZ, Daniel. Finanças Comportamentais e a Hipótese dos Mercados Eficientes. Revista de Economia Contemporânea, Rio de Janeiro, 9(1): 41-72, jan/abr, 2005

ARAÚJO, D. R. de; TIBÚRCIO SILVA, C. A. Aversão à Perda nas Decisões de Risco. In: $3^{\circ}$ Congresso USP Iniciação Científica em Contabilidade, 291, São Paulo, 2006.

COLARELLI, Stephen, SPRANGER, Jennifer L., Hechanova, M. Regina. "Women, Power, and Sex Composition in Small Groups: An Evolutionary Perspective." Journal of Organizational Behavior, 27(2): 163-84. 2006

CROSON, R.; GNEEZY, U. Gender differences in preferences. Working paper, University of Pennsylvania, 2005.

DOHMEN, Thomas; FALK, Armin; HUFFMAN, David; SUNDE, Uwe; SCHUPP Jürgen e WAGNER Gert. "Individual Risk Attitudes: New Evidence from a Large, Representative, Experimentally-Validated Survey." Institute for the Study of Labor Discussion Paper. 2005.

ECKEL, Catherine C; GROSSMAN Philip J. "Sex Differences and Statistical Stereotyping in Attitudes toward Financial Risk." Evolution and Human Behavior, 23(4): 281-95. 2002.

FAMA, Eugene F. Efficient Capital Markets: A review of theory and empirical work, Journal of Finance, Nova York, 1970

HARISSON, G. W; RUTSTROM, E. E. Risk Aversion in the laboratory. Research in Experimental Economics, Volume 12, 41-196, 2008

HOLT, C. A., LAURY, S. K. (2002). Risk aversion and incentive effects. American Economic Review, 92(5), 1644-1655

MACCRIMMON, K.R; D.A. WEHRUNG, D.A; 1986. Taking Risks. The Free Press, New York.

MILANEZ, Y.D. Finanças Comportamentais no Brasil. São Paulo: FEA, 2004. 
Dissertação de Mestrado - Economia das Instituições e do Desenvolvimento, Faculdade de Economia Administração e Contabilidade, São Paulo, 2003.

NEUMANN, J. von; MORGENSTERN, O. Theory of Games and Economic Behavior. Princeton: Princeton University Press, 1944.

OLIVEIRA, E.; SILVA, S. M.; SILVA, W. V. Finanças Comportamentais: um estudo sobre o perfil comportamental do investidor e do propenso investidor. Seminário de Gestão de Negócios. Curitiba: 2005.

PINDYCK, Robert S; RUBINFELD, Daniel L. Microeconomia. 6a ed. São Paulo: Pearson, 2006.

SHAW, Kathryn.L; An Empirical Analysis of Risk Aversion and Income Growth, Journal of Labor Economics,14, pp. 626-653. 1996.

SHEFRIN, Hersh.; STATMAN, M. The disposition to sell winners too early and to ride losers too long: Theory and evidence. Journal of Finance, 1985.

SHEFRIN, Hersh. Beyond Greed and Fear: Understanding behavioral finance and psychology of investing, Oxford University Press, Oxford, 2000.

SHILLER, R. Exuberância Racional. Makron Books. São Paulo, 2000.

SILVA, Wesley. Finanças comportamentais: um estudo sobre o perfil comportamental do investidor e do propenso investidor. RECADM, v. 7, n. 2, 2008.

Smith, Adam. An Inquiry into the Nature and Causes of the Wealth of Nations, Volumes I and II. 1776.

SOUZA, C. A.; KAYO, E. K.; PUSCH, A. C.; YU, A. S. Teoria Da Pespectiva De Kahneman E Tversky: Estudo Empírico Com Alunos De Graduação Em Administração. São Paulo: Faculdade de Economia e Administração da Universidade de São Paulo (FEA/USP), 2008.

TVERSKY, Amos. Elimination by aspects: a theory of choice. Psychological Review, 76, 31-48, 1972

TVERSKY, A., KAHNEMAN, D. (1992). Advances in prospect theory: Cumulative representations of uncertainty. Journal of Risk and Uncertainty, 5, 297-323

TVERSKY, A.; KAHNEMAN, D. The framing of decisions and the psychology of choice. 1981. Science, v.211, No 4481.pp. 453-458. 
TVERSKY, Amos., KAHNEMAN, Daniel. Prospect theory: na analysis of decision under risk. Econometrica 47, 1979.

WEBER, Christoph S.: Cultural Differences in Risk Tolerance. IWE Working Paper 01 Erlangen, 2013.

YOSHINAGA, Claudia Emiko et al. Finanças comportamentais: uma introdução. Revista de Gestão USP, São Paulo, v. 15, n. 3, p. 25-35, jul./set. 2008.

https://repositorio.ufsc.br/bitstream/handle/123456789/94669/Monografia\%20do \%20Vitor\%20Dias\%20da\%20Cunha.pdf?sequence=1\&isAllowed=y 


\section{Anexo 1}

\section{Questionário}

1- Gênero:

- Feminino

- Masculino

Abaixo são apresentadas 10 decisões pareadas para uma loteria com diversos valores esperados. Você tem a opção de jogar na Loteria Opção A e na Loteria Opção B.

Exemplo:

Escolhendo a primeira linha da Opção $A$, teríamos $10 \%$ de chance ganhar $R \$ 6,34$, contra $90 \%$ de chance de ganhar $\mathrm{R} \$ 5,07$. Enquanto na Opção $B$ teríamos $10 \%$ de ganhar $\mathrm{R} \$$ 12,20 e $90 \%$ de chance de ganhar $\mathrm{R} \$ 0,32$.

\begin{tabular}{|c|c|c|c|c|}
\hline & \multicolumn{2}{|c|}{ Opção A } & \multicolumn{2}{|c|}{ Opção B } \\
\hline 1 & $10 \%$ de $R \$ 6,34$ & $90 \%$ de $R \$ 5,07$ & $10 \%$ de RS 12,20 & $90 \%$ de $R \$ 0,32$ \\
\hline 2 & $20 \% 6$ de $R \$ 6,34$ & $80 \$ 6$ de $R \$ 5,07$ & 2056 de $R \$ 12,20$ & $80 \$ 6$ de $R \$ 0,32$ \\
\hline 3 & $30 \%$ de $R \$ 6,34$ & $70 \$ 6$ de $R \$ 5,07$ & $30 \%$ de $R \$ 12,20$ & $70 \%$ de $R \$ 0,32$ \\
\hline 4 & $40 \%$ de $R \$ 6,34$ & $60 \$ 6$ de $R \$ 5,07$ & $40 S 6$ de $R \$ 12,20$ & 6036 de $R \$ 0,32$ \\
\hline 5 & $50 \%$ de $R \$ 6,34$ & $50 \$ 6$ de $R \$ 5,07$ & $50 \%$ de R\$ 12,20 & $50 \%$ de $R \$ 0,32$ \\
\hline 6 & $60 \%$ de $R \$ 6,34$ & $40 \$ 6$ de $R \$ 5,07$ & $60 \% 6$ de RS 12,20 & $40 \$ 6$ de $R \$ 0,32$ \\
\hline 7 & $70 \%$ de $R \$ 6,34$ & $30 \$ 6$ de $R \$ 5,07$ & $70 \%$ de $R \$ 12,20$ & $30 \%$ de $R \$ 0,32$ \\
\hline 8 & $80 \%$ de R\$ 6,34 & $20 \%$ de $R \$ 5,07$ & $80 \%$ de $R S 12,20$ & $20 \%$ de $R \$ 0,32$ \\
\hline 9 & $90 \%$ de $R \$ 6,34$ & $10 \%$ de $R \$ 5,07$ & $90 \%$ de $R \$ 12,20$ & $10 \%$ de $R \$ 0,32$ \\
\hline 10 & 10086 de $R \$ 6,34$ & $0 \% 6$ de $R \$ 5,07$ & $100 \%$ de $R \$ 12,20$ & $0 \% 6$ de $R \$ 0,32$ \\
\hline
\end{tabular}

2- A partir de qual linha você mudaria sua preferência da Opção A para a Opção B?

- 1

- 2

- 3

- 4

- 5
- 6

- 7

- 8

- 9

- 10 
Abaixo, é apresentado outro par de loterias:

\begin{tabular}{|c|c|c|c|c|}
\hline & \multicolumn{2}{|c|}{ Opção A } & \multicolumn{2}{|c|}{ Opção B } \\
\hline 1 & $10 \%$ de $R \$ 126,72$ & $90 \%$ de $\mathrm{R} \$ 101,38$ & $10 \%$ de $R \$ 243,95$ & $90 \%$ de $R \$ 6,34$ \\
\hline 2 & $20 \% 6$ de $R \$ 126,72$ & $80 \% 6$ de $\mathrm{R} \$ 101,38$ & $20 \% 6$ de $R \$ 243,95$ & $80 \%$ de $R \$ 6,34$ \\
\hline 3 & 3056 de $R \$ 126,72$ & $70 \%$ de $\mathrm{R} \$ 101,38$ & $30 \%$ de $R \$ 243,95$ & 7086 de $R \$ 6,34$ \\
\hline 4 & $40 \$ 6$ de $R \$ 126,72$ & 6096 de $\mathrm{R} \$ 101,38$ & $40 \$ 6$ de $R \$ 243,95$ & $60 \%$ de $R \$ 6,34$ \\
\hline 5 & $50 \$ 6$ de $R \$ 126,72$ & 5096 de $\mathrm{R} \$ 101,38$ & $50 \%$ de $R \$ 243,95$ & $50 S 6$ de $R \$ 6,34$ \\
\hline 6 & 6056 de $R \$ 126,72$ & 4056 de $R \$ 101,38$ & 6096 de $R \$ 243,95$ & $40 \$ 6$ de $R \$ 6,34$ \\
\hline 7 & $70 \%$ de $R \$ 126,72$ & $30 \%$ de $R \$ 101,38$ & $70 \%$ de $R \$ 243,95$ & 3086 de $R \$ 6,34$ \\
\hline 8 & $80 \$ 6$ de R\$ 126,72 & 2096 de $R \$ 101,38$ & 8096 de $R \$ 243,95$ & $20 \$ 6$ de $R \$ 6,34$ \\
\hline 9 & $90 \$ 6$ de $R \$ 126,72$ & 1056 de $R \$ 101,38$ & $90 \$ 6$ de $R \$ 243,95$ & 1086 de $R \$ 6,34$ \\
\hline 10 & $100 \%$ de $R \$ 126,72$ & $0 \%$ de $\mathrm{R} \$ 101,38$ & $100 \%$ de $R \$ 243,95$ & $0 \% 6$ de $R \$ 6,34$ \\
\hline
\end{tabular}

3 - A partir de qual linha você mudaria sua preferência da Opção A para a Opção B?

$\begin{array}{ll}\text { - } 1 & -6 \\ \text { - } 2 & -7 \\ \text { - } 3 & \text { - } 8 \\ \text { - } 4 & \text { - } 9 \\ \text { - } 5 & \text { - } 10\end{array}$

Abaixo é apresentado o último par de loterias:

Opção A

\begin{tabular}{ccc}
\hline 1 & $10 \%$ de $R \$ 316,81$ & $90 \%$ de $R \$ 253,45$ \\
2 & $20 \% 6$ de $R \$ 316,81$ & $80 \%$ de $R \$ 253,45$ \\
3 & $30 \%$ de $R \$ 316,81$ & $70 \%$ de $R \$ 253,45$ \\
4 & $40 \% 6$ de $R \$ 316,81$ & $60 \%$ de $R \$ 253,45$ \\
5 & $50 \%$ de $R \$ 316,81$ & $50 \%$ de $R \$ 253,45$ \\
6 & $60 \%$ de $R \$ 316,81$ & $40 \%$ de $R \$ 253,45$ \\
7 & $70 \%$ de $R \$ 316,81$ & $30 \%$ de $R \$ 253,45$ \\
8 & $80 \%$ de $R \$ 316,81$ & $20 \% 6$ de $R \$ 253,45$ \\
9 & $90 \% 6$ de $R \$ 316,81$ & $10 \%$ de $R \$ 253,45$ \\
10 & $100 \% 6$ de $R \$ 316,81$ & O\$6 de $R \$ 253,45$
\end{tabular}

Opção B

\begin{tabular}{|c|c|}
\hline 1086 de $\mathrm{R} \$ 609,86$ & $90 \%$ de $R \$ 15,84$ \\
\hline $20 \%$ de $R \$ 609,86$ & $80 \%$ de RS 15,84 \\
\hline $30 \% 6$ de $R \$ 609,86$ & $70 \% 6$ de $R \$ 15,84$ \\
\hline $40 \%$ de $R \$ 609,86$ & $60 \% 6$ de $R \$ 15,84$ \\
\hline $50 \%$ de R\$ 609,86 & $50 \%$ de $\mathrm{R} \$ 15,84$ \\
\hline $60 \%$ de $R \$ 609,86$ & $40 \%$ de $R \$ 15,84$ \\
\hline $70 \%$ de R\$ 609,86 & $30 \%$ de R\$ 15,84 \\
\hline $80 \%$ de $R \$ 609,86$ & $20 \%$ de $\mathrm{R} \$ 15,84$ \\
\hline $90 \%$ de $R \$ 609,86$ & $10 \%$ de $R \$ 15,84$ \\
\hline $100 \%$ de $\mathrm{R} \$ 609,86$ & O 86 de $R \$ 15,84$ \\
\hline
\end{tabular}

A partir de qual linha você mudaria sua preferência da Opção A para a Opção B?

- 1

- 2

- 3

- 4

- 5
- 6

- 7

- 8

- 9

- 10 